\title{
The Life Cycle of the North Atlantic Storm Track*
}

\author{
Lenka Novak, MaArten H. P. Ambaum, And Rémi Tailleux \\ Department of Meteorology, University of Reading, Reading, United Kingdom
}

(Manuscript received 2 April 2014, in final form 24 September 2014)

\begin{abstract}
The North Atlantic eddy-driven jet exhibits latitudinal variability with evidence of three preferred latitudinal locations: south, middle, and north. Here the authors examine the drivers of this variability and the variability of the associated storm track. The authors investigate the changes in the storm-track characteristics for the three jet locations and propose a mechanism by which enhanced storm-track activity, as measured by upstream heat flux, is responsible for cyclical downstream latitudinal shifts in the jet. This mechanism is based on a nonlinear oscillator relationship between the enhanced meridional temperature gradient (and thus baroclinicity) and the meridional high-frequency (periods of shorter than 10 days) eddy heat flux. Such oscillations in baroclinicity and heat flux induce variability in eddy anisotropy, which is associated with the changes in the dominant type of wave breaking and a different latitudinal deflection of the jet. The authors' results suggest that high heat flux is conducive to a northward deflection of the jet, whereas low heat flux is conducive to a more zonal jet. This jet-deflecting effect was found to operate most prominently downstream of the storm-track maximum, while the storm track and the jet remain anchored at a fixed latitudinal location at the beginning of the storm track. These cyclical changes in storm-track characteristics can be viewed as different stages of the storm track's spatiotemporal life cycle.
\end{abstract}

\section{Introduction}

A key feature of terrestrial storm tracks is that they are generally accompanied by a deep tropospheric jet primarily driven by the momentum convergence produced by the storm tracks' high-frequency baroclinic eddies (Hoskins et al. 1983). This three-dimensional momentum convergence can be visualized using the divergence of the $\mathbf{E}$ vectors (Hoskins et al. 1983). The $\mathbf{E}$ vector indicates the direction of eddy propagation (which is opposite to the direction of the westerly momentum transfer by eddies) and is defined as

$$
\mathbf{E}=\left(\overline{v^{\prime 2}-u^{\prime 2}},-\overline{u^{\prime} v^{\prime}}, \frac{f}{\partial \theta / \partial p} \overline{v^{\prime} \theta^{\prime}} \propto \overline{v^{\prime} T^{\prime}}\right),
$$

where the first two terms are the horizontal barotropic components and the last term is the vertical baroclinic

\footnotetext{
* Supplemental information related to this paper is available at the Journals Online website: http://dx.doi.org/10.1175/JAS-D-14-0082.s1.

Corresponding author address: Lenka Novak, Department of Meteorology, University of Reading, P.O. Box 243, Reading RG6 6BB, United Kingdom.

E-mail: 1.novakova@pgr.reading.ac.uk
}

component that is proportional to the lower-level meridional heat flux $\overline{v^{\prime} T^{\prime}}$ (referred to herein as "heat flux"). The overbar indicates a time average and the prime denotes a perturbation from that average. Hoskins et al. (1983) observe that for high-frequency (with period of 10 days and lower) eddies the $\mathbf{E}$ vectors tend to point upward at the beginning of the storm track and subsequently become more horizontal and meridionally divergent toward the middle of the storm track. This means that at the beginning of the storm track the eddies transfer momentum to lower levels reducing the vertical wind shear, whereas farther downstream, the eddies are responsible for a more barotropic variability in the jet. The authors also showed that the two horizontal $\mathbf{E}$-vector components are strongly dependent on eddy anisotropy, such as tilt and aspect ratio. The reader is referred to Hoskins et al. (1983) and Orlanski (1998) for a more detailed description of these two components and their relationship with eddy anisotropy. Variability in the eddy anisotropy was further linked to different dominant types of wave breaking by the idealized experiments of Rivière (2009) and Orlanski (2003), corroborating the observations of a northward jet during enhanced anticyclonic wave breaking on the equatorward side of the jet and a southern jet during enhanced cyclonic wave breaking on the poleward side of the jet (Woollings et al. 2008, 2010; Franzke et al. 2011). 
The above research suggests that transitions between different dominant types of wave breaking are crucial for altering the downstream course of the jet. Anticyclonic wave breaking is dominant on a sphere by default (e.g., Rivière 2009), which can be seen by studying the structure of the terrestrial eddy-driven jets spiraling toward the poles. Several different mechanisms have been suggested for the transitions to the dominance of cyclonic breaking, including increasing the initial cyclonic barotropic shear of the jet (Thorncroft et al. 1993), enhancing the vertical shear in the lower stratosphere (Wittman et al. 2007), and strengthening the lower-level baroclinicity (Namias 1950; Orlanski 2003; Rivière 2009). The latter effect is of interest as recent observational and conceptual studies (e.g., Thompson and Birner 2012; Ambaum and Novak 2014, hereafter AN) have suggested that the upstream temperature gradient (and thus baroclinicity) is considerably reduced and replenished in time owing to the fluctuations in the storm-track activity itself. AN suggest a mechanism whereby a diabatic forcing [such as land-sea contrast, possibly enhanced by the presence of a western boundary current and orography (Brayshaw et al. 2011)] continuously increases baroclinicity, which provides favorable conditions for eddy growth leading to high storm-track activity. As the storm-track activity increases substantially, the baroclinicity starts to be eroded owing to the vigorous mixing of the temperature gradients by eddies. Once baroclinicity reaches very low levels, further production of new eddies becomes limited. The resultant low storm-track activity then allows the baroclinicity to increase again because of the diabatic forcing and the cycle repeats. This nonlinear relationship results in an oscillatory behavior that is concealed in the time-mean picture and may not be initially obvious from the apparently unpredictable and chaotic behavior of the system. We use the above reasoning to hypothesize that this cyclical variability in the storm-track activity and baroclinicity should have a dual role in modifying the North Atlantic jet. The first upstream role is the mixing of temperature gradients by storm-track activity leading to a fluctuating vertical shear (by thermal wind balance). The second downstream role is that the cyclical variations in the upstream storm-track activity cause a different wave breaking type to dominate, inducing latitudinal shifts in the downstream jet.

To test these hypotheses linking different properties of the storm track to the latitudinal variability in the jet, we need some observational characterization of the latter. Recently, Woollings et al. (2010) and Franzke et al. (2011) demonstrated, based on the analysis of lower-level wind maxima in the 40-yr European Centre for Medium-Range Weather Forecasts (ECMWF)
Re-Analysis (ERA-40) data, that the latitudinal variations of the eddy-driven jet in the North Atlantic region could be partitioned into three "persistent" and "recurrent" regimes, labeled south $(\mathrm{S})$, middle $(\mathrm{M})$, and north $(\mathrm{N})$ regimes. As these regimes conveniently characterize the latitudinal variability of the eddy-driven jet, they are adopted here to study the spatiotemporal variability of the storm-track and flow characteristics.

Section 2 investigates the direct effect of storm-track activity variations during the jet regimes on baroclinicity and the associated baroclinic jet structure. Section 3 then explores the downstream effect of the upstream storm-track activity and baroclinicity variations on the eddy structure, the associated horizontal E-vector components, and the barotropic deflection of the jet. Section 4 combines these findings and reveals a sequence of different stages of a cyclic evolution, a life cycle, of the storm track in space and time. We propose that this life cycle is associated with a latitudinally fixed upstream pulsation of storm-track activity that drives downstream shifts in the latitude of the storm track and the associated jet. A discussion of the transition to lower-frequency time scales that leads to this life cycle, as well as the extent to which this mechanism is local, is also provided in section 4 , along with concluding remarks.

\section{Upstream baroclinic effect}

The analyses carried out in this and the following sections are all based on the daily-averaged DecemberFebruary (DJF) data from the ERA-40 (1957-2002) dataset [as per Uppala et al. (2005)]. Throughout this study, we use Frame et al.'s (2011) $k$-means clustering of the latitudinal jet profiles (zonally and vertically averaged between $0^{\circ}$ and $60^{\circ} \mathrm{W}$ and between 700 and $925 \mathrm{hPa}$ ) to partition the data into the three jet regimes. Note that since the eddy-driven jet is deep, the lowerlevel zonal wind is used to identify its location and separate it from the shallow subtropical jet. This partitioning method is slightly different to that of Woollings et al. (2010) and Franzke et al. (2011), who used partitioning based on the latitudinal variability of the maximum low-frequency zonal wind. The former method was preferred because it does not require the large-scale flow variability to be based on low-frequency filtering and because it is more robust when applied to different datasets (Frame et al. 2011). This partition method yields 1174 occurrences in the $\mathrm{S}$ regime, 1521 in the $\mathrm{M}$ regime, and 1355 in the $\mathrm{N}$ regime. The reader is referred to Frame et al.'s (2011) study for further details of this partitioning method.

We used meridional heat flux and the maximum Eady growth rate to investigate the variability in storm-track 


\section{heat flux}
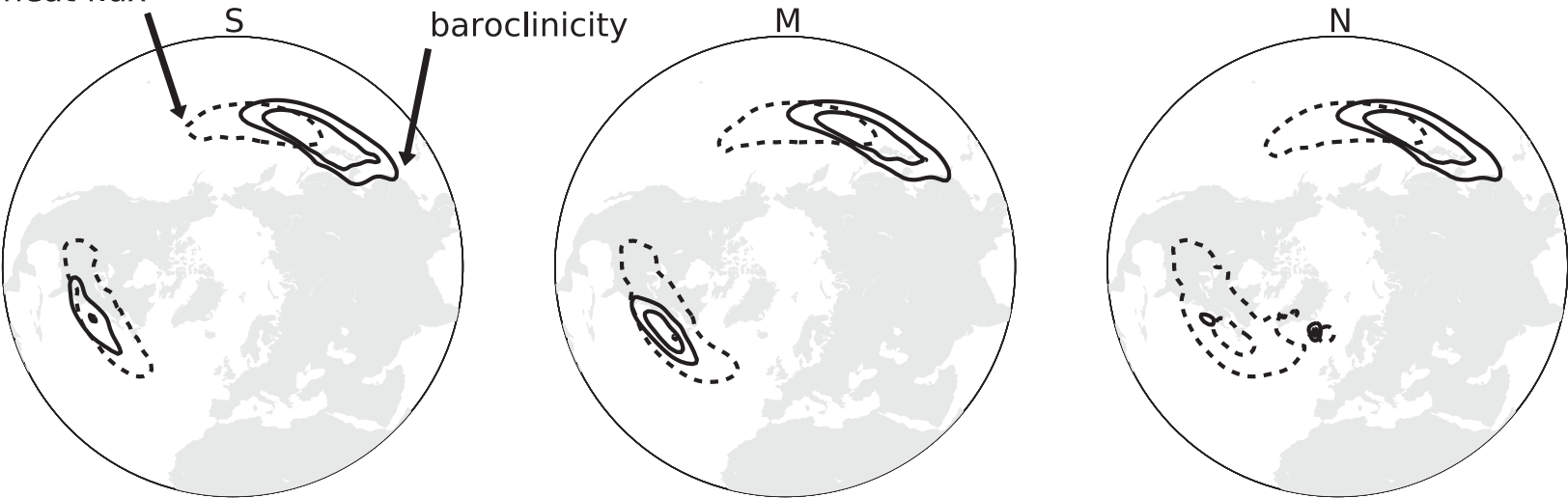

FIG. 1. Hemispheric composites of baroclinicity (solid contours for 0.7 and 0.8 days $^{-1}$ ) and heat flux (dashed contours for 10 and $20 \mathrm{~K} \mathrm{~m} \mathrm{~s}^{-1}$ ) for the S, M, and $\mathrm{N}$ regimes. Please see supplemental material at http://dx.doi.org/10.1175/JAS-D-14-0082.s1 for a color version of these composites and the associated 1000-500-hPa thickness and thickness anomaly fields.

activity and baroclinicity (related to the meridional temperature gradient), respectively. The meridional heat flux, calculated using perturbations from a 10-day low-pass running mean based on Duchon's (1979) Lanczos filter of vertically averaged (between 700 and $925 \mathrm{hPa}$ ) meridional velocity and temperature, was used to represent the storm-track activity that is associated with high-frequency eddies (Lorenz and Hartmann 2003). The maximum Eady growth rate at $775 \mathrm{hPa}$, based on vertical zonal wind shear and a variable static stability parameter [as in James (1994)], is defined as

$$
\sigma=0.31 \frac{f}{N} \frac{\partial u}{\partial Z}
$$

where $f$ is the Coriolis parameter, $N$ is the static stability parameter, and $Z$ is the geopotential height. The static stability parameter for dry atmosphere was used as most of the variance across the regimes was found to be associated with changes in wind shear.

The partitioned heat flux and baroclinicity were then averaged for each jet regime to produce three composites
(Fig. 1). Neither the region of maximum heat flux nor the region of enhanced baroclinicity move latitudinally with the jet to any significant extent until the very downstream end of the storm track. This latitudinal confinement is displayed more explicitly in Fig. 2. In terms of intensity, these two quantities are clearly not proportional to each other as may be suggested by the time-mean picture discussed in many studies (e.g., Hoskins and Valdes 1990; Orlanski 1998). Instead, the heat flux intensity increases with the jet's latitude while the baroclinicity is most intense during the $\mathrm{M}$ regime and least intense during the $\mathrm{N}$ regime, as is evident from Fig. 2. Note that in Fig. 2a, the relative angular momentum represents latitudinally weighted lower-level zonal wind $(r=u a \cos \phi)$. In terms of the variability within the regimes, a closer inspection of the probability distribution functions (PDFs) of baroclinicity (not shown) and heat flux (investigated in the next section) has revealed that although all the regimes exhibit a wide range of both baroclinicity and heat flux values, the above variability between the regimes is still apparent and is not caused by sampling issues. Note that there is (a)

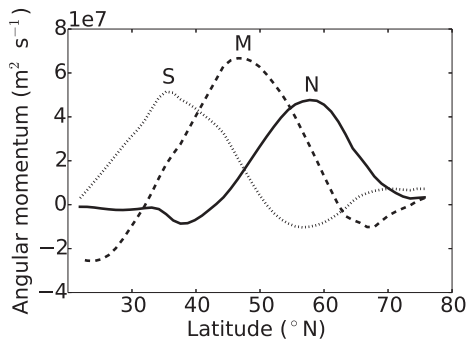

(b)

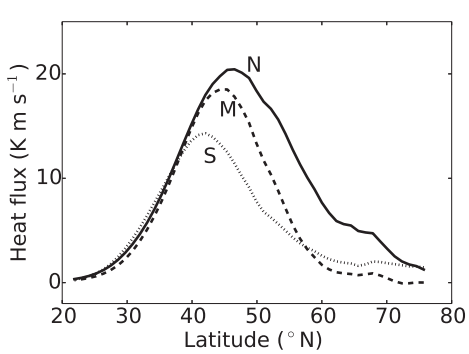

(c)

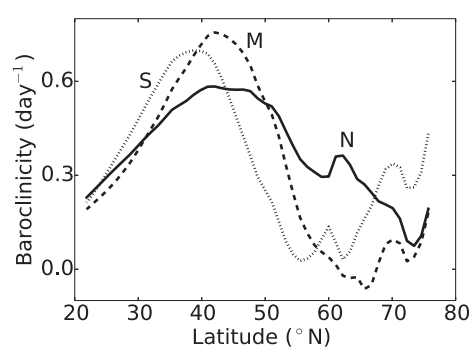

FIG. 2. Composites of latitudinal profiles of the (a) lower-level relative angular momentum $\left(\mathrm{m}^{2} \mathrm{~s}^{-1}\right.$; averaged between $0^{\circ}$ and $\left.30^{\circ} \mathrm{W}\right)$, (b) heat flux $\left(\mathrm{K} \mathrm{m} \mathrm{s}^{-1}\right.$; averaged between $40^{\circ}$ and $\left.70^{\circ} \mathrm{W}\right)$, and (c) baroclinicity (day ${ }^{-1}$; averaged between $30^{\circ}$ and $\left.90^{\circ} \mathrm{W}\right)$ for the $\mathrm{S}(\mathrm{dotted})$, $\mathrm{M}$ (dashed), and $\mathrm{N}$ (solid) regimes. 
very little variability in both heat flux and baroclinicity outside of the North Atlantic region. This aspect will be investigated further in the next section.

Franzke et al. (2011) propose that the preferred transitions between the jet regimes are from $\mathrm{M}$ to $\mathrm{N}, \mathrm{N}$ to $\mathrm{S}$, and $\mathrm{S}$ to $\mathrm{M}$ regimes. Assuming this sequence of transitions, the above temporal relationship between heat flux and baroclinicity is reminiscent of that proposed by AN, which was described in the introduction. In AN's study a large but short-lived (lasting approximately 2 days) heat flux event erodes baroclinicity, which eventually limits further baroclinic instability and the associated heat flux growth. The reduced heat flux then allows the continuous replenishment of baroclinicity by diabatic forcings to dominate until heat flux starts to increase again and the cycle repeats. We suggest that this nonlinear oscillator model can also assist in the interpretation of the variability of heat flux and baroclinicity on the longer time scale of the jet regimes. This issue of time scales will be further addressed in the next section. An additional difference is that while AN used the unfiltered $v^{\prime} T^{\prime}$ to study short-lived spikelike heat flux events, here we are using its time-filtered value $\overline{v^{\prime} T^{\prime}}$. The latter is proportional to the vertical $\mathbf{E}$-vector component and can therefore be easily related to the existing theoretical frameworks. The time-filtered heat flux can be viewed as an accumulation of smaller heat flux events or one particularly large event (this will be shown in the next section). We therefore propose a mechanism whereby explosive rapidly deepening cyclones are initiated during the $\mathrm{M}$ regime owing to its high baroclinicity (Sanders and Gyakum 1980). The cyclones then develop further during the $\mathrm{N}$ regime while mixing the temperature gradients and therefore reducing baroclinicity to very low values. This is followed by a recovery of baroclinicity during the $\mathrm{S}$ regime when the eddy activity is limited (Rivière and Orlanski 2007). A similar mechanism, whereby slow-moving waves are associated with the strengthening and relaxation of the meridional temperature gradient (i.e., baroclinicity) in the storm-track region, has been linked to the fluctuations in the zonal wind index in Namias' (1950) study. In the next section, we are interested in whether this nonlinear oscillator mechanism can help to explain the existence of the jet regimes and the transitions between them.

\section{Downstream barotropic effect}

Rivière's (2009) and Orlanski's (2003) studies suggest that variations in baroclinicity can induce variations in eddy anisotropy and different dominant types of wave breaking that lead to shifts in the jet latitude. This section tests whether variations in these eddy and jet characteristics can be observed during the jet regimes and whether the above nonlinear oscillatory relationship between baroclinicity and heat flux can explain the preferred cycling between the jet regimes.

Orlanski's (2003) study proposes that anticyclonic breaking is dominant if the cyclonic eddies are more southwest-northeast (SW-NE) tilted and meridionally elongated, while cyclonic breaking is more characteristic of rounder cyclonic eddies tilted in the southeastnorthwest (SE-NW) direction. Different types of wave breaking were thus identified here using Ertel PV on the 315-K isentrope, eddy tilt $\alpha$, and aspect ratio $\epsilon$ along the rotated coordinates relative to the eddy tilt. The two latter quantities were calculated for the $250-\mathrm{hPa}$ level as per James (1994):

$$
\begin{aligned}
& \alpha=\frac{1}{2} \tan ^{-1}\left(\frac{2 \overline{u^{\prime} v^{\prime}}}{\overline{v^{2}}-\overline{u^{\prime 2}}}\right) \text { and } \\
& \epsilon=\frac{\overline{\left(u^{\prime} \sin \alpha+v^{\prime} \cos \alpha\right)^{2}}}{\overline{\left(u^{\prime} \cos \alpha-v^{\prime} \sin \alpha\right)^{2}}},
\end{aligned}
$$

where the eddy tilt represents the angle between the minor axis of a meridionally elongated eddy and the circle of latitude, with positive values representing a SW-NE eddy tilt. The eddy aspect ratio represents the extent to which the meridionally elongated eddies are stretched and is a ratio between their major and minor axes.

As expected, Fig. 3 shows that eddies exhibit a SWNE tilt (indicative of anticyclonic breaking) on the equatorward side and a SE-NW tilt (indicative of cyclonic breaking) on the poleward side of the storm-track region, as the eddies supply momentum toward the jet core and accelerate it. However, it is clear that the SWNE tilting of the $\mathrm{N}$ regime is most spatially extensive, especially in the eastern North Atlantic. The tilting patterns of the $\mathrm{S}$ and $\mathrm{M}$ regimes are more latitudinally constrained across the basin with the SE-NW tilting being more extensive during the $\mathrm{S}$ regime. The aspect ratio anomaly maximum moves more northwest toward the center of the storm track with increasing jet latitude. It is thus likely that the low baroclinicity of the $\mathrm{N}$ regime is not sufficient to maintain coherent eddies, leading to eddy deformation and breaking farther upstream. The high eddy stretching and extensive SW-NE tilting in the $\mathrm{N}$ regime are indicative of anticyclonic breaking. Conversely, in the $\mathrm{M}$ regime the eddies are less stretched in the region of the most intense storm-track activity and baroclinicity, only beginning to deform considerably farther downstream. The S regime exhibits even less stretched and more coherent eddies within the most 
(a)

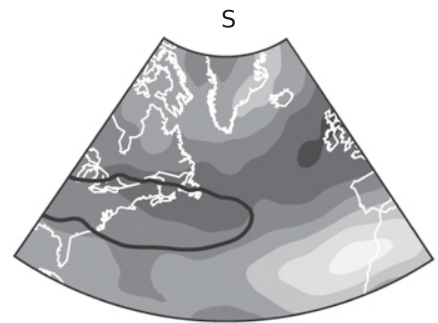

(d)

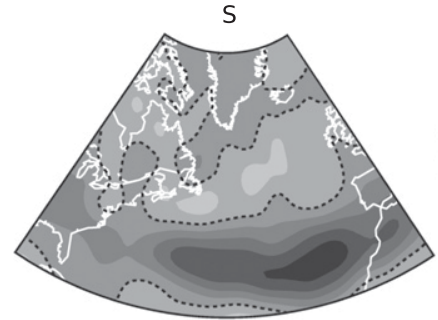

(b)

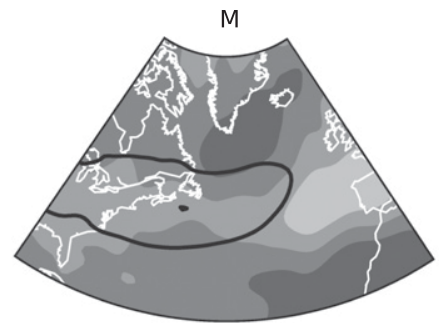

(e)

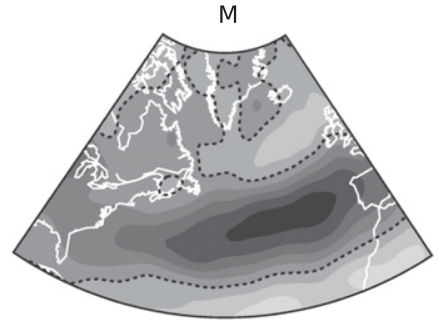

(c)

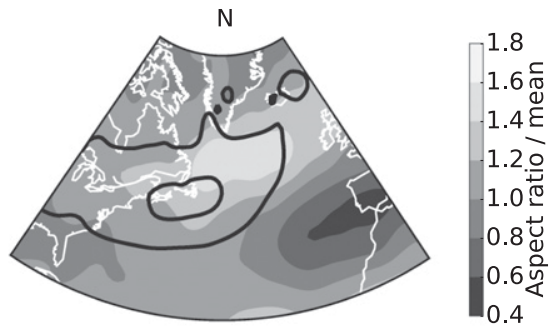

(f)

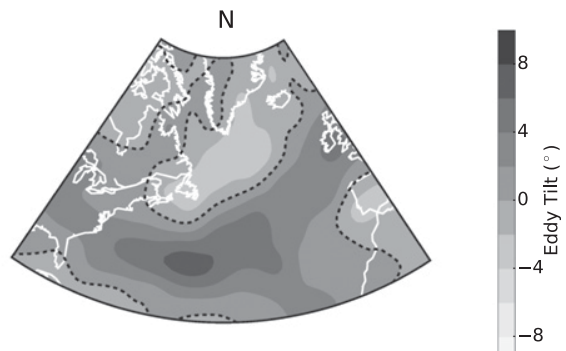

FIG. 3. Composites of the upper-level $(250 \mathrm{hPa})$ eddy aspect-ratio anomaly (computed by dividing the aspect ratio by its climatological mean) for the (a) S, (b) M, and (c) N regimes and the upper-level (250 hPa) eddy tilt for the (d) S, (b) M, and (f) N regimes. The black solid contours show the location of the storm track (measured by heat flux as in Fig. 1) and the dashed black line marks the $0^{\circ}$-tilt contour. Please see supplemental material at http://dx.doi.org/10.1175/JAS-D-14-0082.s1 for a color version of these composites and the associated streamfunction anomaly field.

intense part of the storm track as baroclinicity is being replenished in the absence of strong eddy mixing (as is evident from the low heat flux values). The reduced stretching and relatively extensive SE-NW tilting are indicative of cyclonic breaking. These patterns of eddy anisotropy therefore indicate that the $\mathrm{N}$ regime experiences anticyclonic breaking farther upstream and more extensively than the other two regimes. The $\mathrm{S}$ regime has the most dominant cyclonic component with the two types of tilting being most symmetric about the latitude circle. The $\mathrm{M}$ regime appears to be strongly influenced by both types of wave breaking. These patterns are consistent with those found by Franzke et al. (2011).

In support of these interpretations, the large-scale flow pattern is shown in Fig. 4 using composites of the upper-level Ertel potential vorticity (PV) distribution
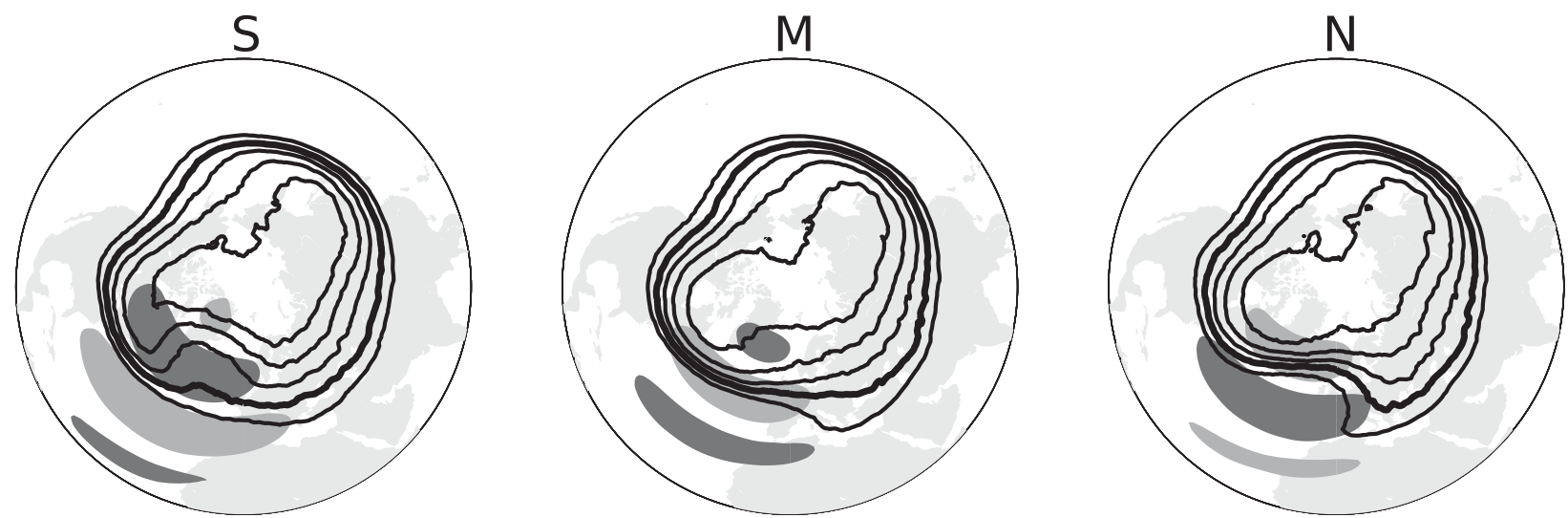

FIG. 4. The composites (medians) of Ertel PV on the 315-K isentrope for the S, M, and N regimes. Contours have an interval of $1 \mathrm{PVU}$ and the thick line marks the 2-PVU contour. The shading represents upper-level $(250 \mathrm{hPa})$ zonal wind anomalies from the climatological mean (light shading: $5 \mathrm{~m} \mathrm{~s}^{-1}$ and above; dark shading: $-5 \mathrm{~m} \mathrm{~s}^{-1}$ and below). A pattern correlation analysis of the PV distribution (not shown) confirmed that the averaged correlations between individual instances belonging to a particular regime are greater for that regime than those for the other regimes, confirming that these patterns are statistically robust. Please see supplemental material at http://dx.doi.org/10.1175/JAS-D-14-0082.s1 for a color version of these composites and the associated horizontal wind and pressure fields. 
TABLE 1. Pattern correlation scores for the PV anomaly for the S, $\mathrm{M}$, and $\mathrm{N}$ jet regimes for the Atlantic sector.

\begin{tabular}{lrrr}
\hline \hline & $\mathrm{S}$ & $\mathrm{M}$ & \multicolumn{1}{c}{$\mathrm{N}$} \\
\hline $\mathrm{S}$ & 1.00 & -0.42 & -0.27 \\
$\mathrm{M}$ & -0.42 & 1.00 & 0.16 \\
$\mathrm{~N}$ & -0.27 & 0.16 & 1.00 \\
\hline
\end{tabular}

and the zonal wind anomalies from the climatological mean at upper levels $(250 \mathrm{hPa}$, therefore including anomalies associated with the subtropical jet) for the three regimes. The median was used for the PV composites instead of the mean so as to retain the sharp PV gradient, making the composites more structurally correct. The 2-PVU line represents the dynamical tropopause and the sharpest PV gradient indicates the location of the upper-level jet. The $\mathrm{S}$ regime exhibits a fairly zonal jet and a strong easterly wind anomaly north of the jet. This indicates a strong trough over the western Atlantic with the ridge in the eastern Atlantic being stretched in the SE-NW direction relative to the latitude circle toward Greenland (corresponding to cyclonic wave breaking). On the other hand, the $\mathrm{N}$ regime exhibits a split flow and a more pronounced ridge downstream of the storm track, which tilts the troughridge structure in the opposite direction (corresponding to anticyclonic wave breaking). This figure also shows that PV patterns vary only weakly outside of the North Atlantic region, indicating statistical robustness of our results as well as the fact that the far upstream flow is not systematically linked to the persistence of these regimes. This is shown more quantitatively in Tables 1 and 2, which show the spatial correlation scores [calculated as per von Storch and Zwiers (1999)] for PV anomalies (from the climatological mean) in the Atlantic $\left(30^{\circ}-\right.$ $\left.70^{\circ} \mathrm{N}, 0^{\circ}-80^{\circ} \mathrm{W}\right)$ and Pacific $\left(30^{\circ}-70^{\circ} \mathrm{N}, 140^{\circ} \mathrm{E}-130^{\circ} \mathrm{W}\right)$ sectors of the composites in Fig. 4. Similar and more pronounced patterns have been observed in the lowerlevel geopotential thickness (see Fig. 1 of the supplemental material at http://dx.doi.org/10.1175/JAS-D-14-0082.s1) and absolute vorticity distributions (not shown)-the latter of which additionally indicates both types of breaking during the $\mathrm{M}$ regime.

Having established that the jet regimes do exhibit different eddy anisotropy and different dominant types of wave breaking, it is of interest to investigate whether these changes in eddy characteristics lead to the jet shifts rather than just resulting from them. As mentioned in the introduction, the horizontal $\mathbf{E}$-vector components usefully indicate the eddies' barotropic influence on the mean flow and they can both be involved in shifting the jet. By the E-vector definition [Eq. (1)], both components are dependent on eddy tilt and aspect ratio
TABLE 2. Pattern correlation scores for the PV anomaly for the S, $\mathrm{M}$, and $\mathrm{N}$ jet regimes for the Pacific sector.

\begin{tabular}{lccc}
\hline \hline & $\mathrm{S}$ & $\mathrm{M}$ & $\mathrm{N}$ \\
\hline $\mathrm{S}$ & 1.00 & 0.95 & 0.88 \\
$\mathrm{M}$ & 0.95 & 1.00 & 0.92 \\
$\mathrm{~N}$ & 0.88 & 0.92 & 1.00 \\
\hline
\end{tabular}

(Hoskins et al. 1983; Orlanski 1998). This dependence, however, is not the same for the two components. For example, the zonal component can be altered considerably by meridional stretching and zonal thinning of an eddy, while the meridional component remains largely unchanged by the form of eddy decay (Orlanski 1998). It was shown by Orlanski (1998) that the meridional E-vector component denotes the negative meridional momentum flux and its divergence indicates flow acceleration (or latitudinal deviation if the divergence is not symmetrical about the jet axis), while the zonal component promotes a quadrupole structure in the flow. Combining the averages of these two components organizes the flow into a structure reminiscent of the timemean trough-ridge pattern observed above both the Atlantic and Pacific Ocean basins (Orlanski 1998). Both the divergence of these two components and their relative magnitude are therefore important for determining the deflection of the jet.

The composites of the $\mathbf{E}$-vector components averaged for the jet regimes are shown in Fig. 5. The meridional momentum convergence (indicating the location of the jet axis) is also displayed. Using Orlanski's (1998) theory, the large zonal component and the relatively large northward momentum flux of the $\mathrm{N}$ regime imply a northward deflection of the jet, as the trough-ridge structure becomes more pronounced. The meridional momentum convergence is relatively small and peaks at the beginning of the storm track, indicating a low jet speed downstream of the storm track during this regime. The $\mathrm{M}$ regime has a weaker zonal component but stronger poleward momentum flux compared to the $\mathrm{N}$ regime. However, Orlanski (1998) finds that the zonal component is more effective at deflecting the jet north in the North Atlantic, which would explain why the jet is at a lower latitude in the $\mathrm{M}$ regime than during the $\mathrm{N}$ regime. The $\mathrm{M}$ regime also exhibits a large convergence of the meridional momentum toward the downstream end of the storm track, resulting in strong flow acceleration there, as observed. During the $\mathrm{S}$ regime both the zonal component and the poleward momentum flux are relatively small and more zonally symmetrical along the latitude circle compared to the other two regimes, resulting in a relatively zonal jet. These inferences concur with direct observations of the jet from the reanalysis 
(a)

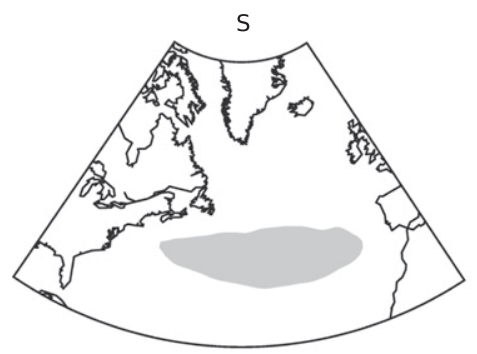

(d)

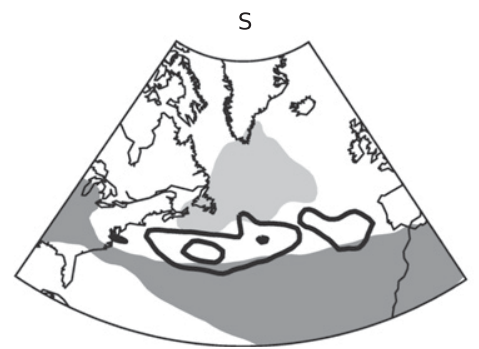

(b)

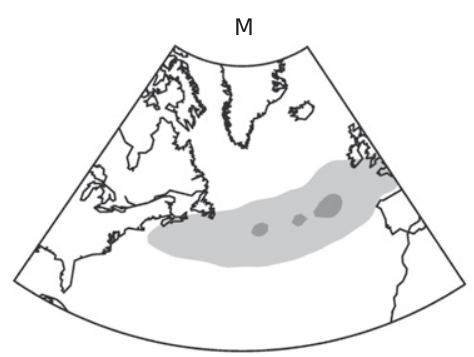

(e)

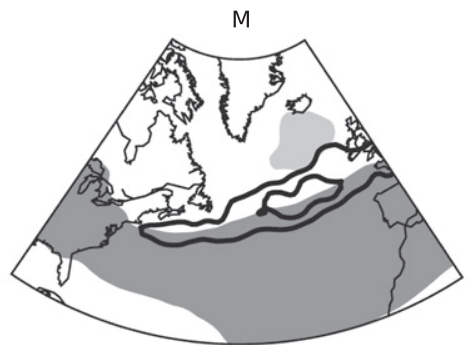

(c)

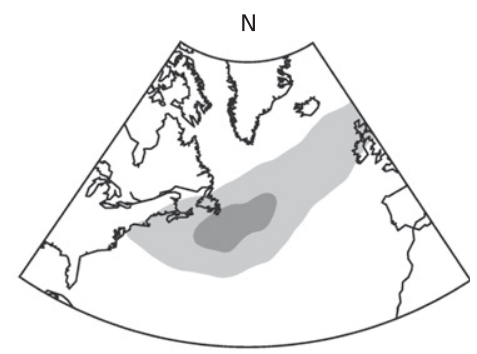

(f)

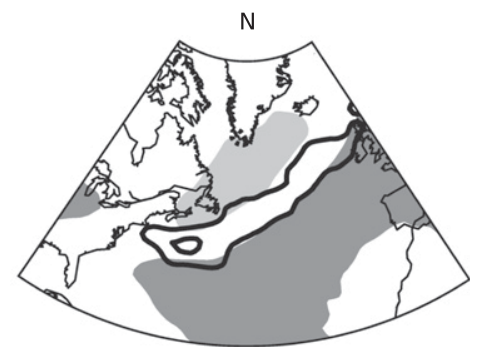

FIG. 5. Composites of the horizontal E-vector components for the (a),(d) S, (b),(e) M, and (c),(f) N regimes. (a)-(c) The zonal component (light shading: values between 80 and $130 \mathrm{~m}^{2} \mathrm{~s}^{-2}$; dark shading: values above $130 \mathrm{~m}^{2} \mathrm{~s}^{-2}$ ) and (d)-(f) the meridional component (dark shading: values below $-15 \mathrm{~m}^{2} \mathrm{~s}^{-2}$; light shading: values above $15 \mathrm{~m}^{2} \mathrm{~s}^{-2}$ ). The momentum convergence is shown by thick black contours $\left(3 \times 10^{-5}\right.$ and $\left.5 \times 10^{-5} \mathrm{~m} \mathrm{~s}^{-2}\right)$. Please see supplemental material at http://dx.doi.org/10.1175/JAS-D-14-0082.s1 for a color version of these composites and the associated horizontal wind field.

data, implying that the eddies are, at least to some extent, responsible for this variability of the jet latitude and intensity.

The above results suggest that through an upstream effect of reducing the baroclinicity, variations in heat flux induce changes in eddy properties that steer the jet to different latitudes farther downstream. To confirm this directly, the PDF of the heat flux was split into the three jet regimes (Fig. 6). It is apparent that the $\mathrm{S}$ regime is most dominant when the heat flux is low and the $\mathrm{N}$ regime is most dominant when the heat flux is high.

To investigate whether this apparent relationship between the upstream heat flux and the downstream jet can be used to indicate the jet deflection from the heat flux values alone, the heat flux PDF was further divided into terciles, which were then used to split the time series of the lower-level latitudinal profiles of the downstream jet (as in Fig. 2). Averaging the profiles of each heat flux tercile produces three profile composites, as shown in Fig. 7. The highest heat flux tercile yields the most northern jet, whereas the lowest tercile yields the most southern jet. The differences between the jet latitudes are not as extreme as those defining the jet regimes (Fig. 2a). This is, however, expected since the latter was partitioned optimally to show the latitudinal deviations of the jet. Additionally, partitioning the PDF into terciles is not wholly representative of the frequency at which the jet regimes occur. In reality, the $\mathrm{M}$ regime is found to be most common while the $\mathrm{N}$ regime is found to be least common (Franzke et al. 2011). It can nevertheless be concluded that heat flux has a strong downstream barotropic influence on the jet's latitudinal position.

This analysis was repeated using a 5-day cutoff Lanczos filter to define eddies. Although the results were similar, the equivalent figure to Fig. 7 (not shown) showed a less-well-defined separation between the zonal wind profiles, with the profiles of the high and middle terciles almost merging at the same latitude. This corroborates Rivière and Orlanski's (2007) findings that the intermediate-frequency (with a period between 5 and 12 days) synoptic eddies are strongly associated with anticyclonic breaking and therefore northward deflection of the jet, so that their removal leads to a less-well-defined northward jet deflection.

A better understanding of the extent to which heat flux affects the downstream behavior of the flow can be achieved by comparing the flow observed during the jet regimes and that observed for the heat flux terciles. Figure 8 shows composites of streamfunction anomalies from the climatological mean averaged for the three respective regimes and heat flux terciles. As expected from the literature (e.g., Woollings et al. 2010), the jet regime composites show similar patterns to the teleconnections. Although somewhat weaker, the heat flux terciles also produce meridionally oriented barotropic 


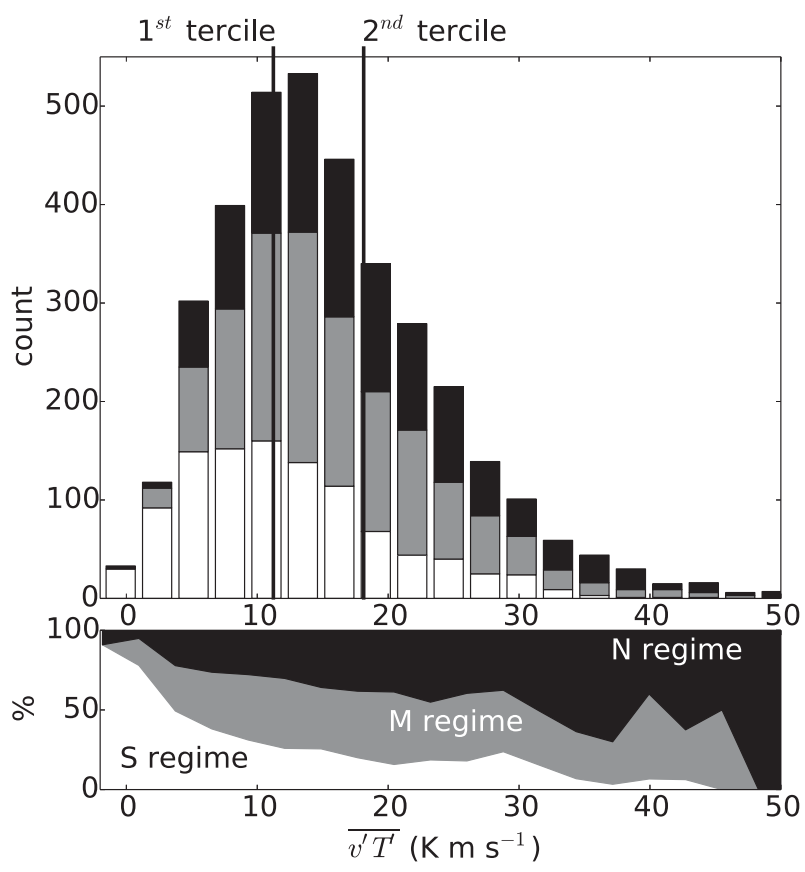

FIG. 6. PDF of the 10-day filtered heat flux (averaged between $35^{\circ}$ and $50^{\circ} \mathrm{N}$ and between $40^{\circ}$ and $70^{\circ} \mathrm{W}$ ) showing the occurrences of the $\mathrm{S}$ (white), $\mathrm{M}$ (gray), and $\mathrm{N}$ (black) jet regimes including the division of the PDF into terciles, with (bottom) the relative importance of the regimes (as a percentage) in each bin.

patterns very similar to those of the jet regimes. Pattern correlation scores [calculated as per von Storch and Zwiers (1999)] are shown in Tables 3 and 4 for a more quantitative comparison. The $\mathrm{S}$ jet regime therefore corresponds to the lowest heat flux tercile, the $\mathrm{M}$ regime to the middle heat flux tercile, and the $\mathrm{N}$ regime corresponds to the highest heat flux tercile. The similarity between the $\mathrm{S}$ regime and the low-heat-flux tercile is strongest. This can be explained by inspecting the heat flux PDF (Fig. 6), which suggests that low values are almost entirely dominated by the $\mathrm{S}$ regime, whereas in the higher part of the PDF, the $\mathrm{N}$ regime dominates but the $\mathrm{M}$ regime is also common. In addition to this, the streamfunction patterns in the $\mathrm{M}$ and $\mathrm{N}$ regimes are more strongly anticorrelated with the $\mathrm{S}$ regime than with each other (not shown). This agrees with the finding of Woollings et al. (2010) that while the $\mathrm{S}$ regime resembles the negative phase of the NAO, the other two regimes both weakly project onto the positive phase of the NAO. This implies that the $\mathrm{S}$ regime is more separable from the other two regimes. Furthermore, the partition into heat flux terciles is not fully representative of the frequency at which the regimes occur and could therefore be another source of the $\mathrm{M}$ and $\mathrm{N}$ regimes not being as strongly correlated with the their respective heat flux terciles. The upper-level PV and absolute vorticity

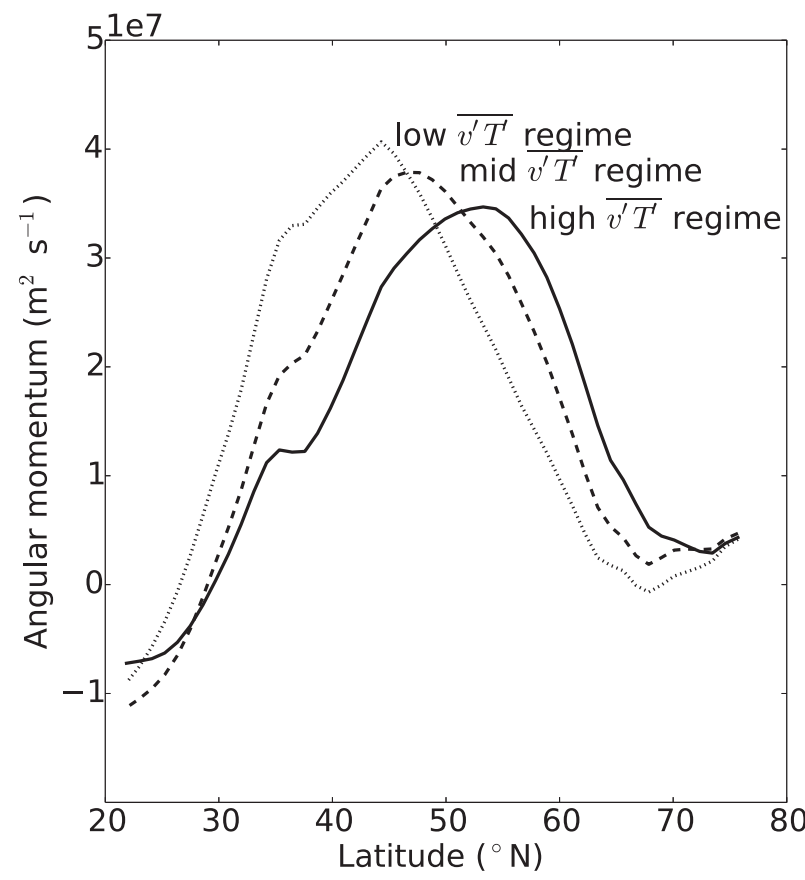

FIG. 7. Composites of the lower-level relative angular momentum profiles (averaged between $0^{\circ}$ and $30^{\circ} \mathrm{W}$ and between 925 and $700 \mathrm{hPa}$ ) averaged for the low (dotted line), middle (dashed line), and high (solid line) heat flux terciles.

composites equivalent to Fig. 8 (not shown) also revealed a considerable similarity between the jet regimes and heat flux terciles.

It is worth noting that using the unfiltered $v^{\prime} T^{\prime}$ (as used in AN) to partition the time series into heat flux terciles yields streamfunction anomaly composites that produce zonally oriented baroclinic wave trains (not shown). This implies that the transition from baroclinic- to barotropic-flow structures is associated with a transition to lower-frequency variability. In other words, while the reduction in the baroclinicity (and thus wind shear) may promptly respond to individual $v^{\prime} T^{\prime}$ events, as shown by AN, the barotropic effect significantly shifting the jet's latitude operates predominantly at lower frequencies of the filtered $\overline{v^{\prime} T^{\prime}}$. In support of this, latitudinal profile composites of the lower-level jet (averaged between 700 and $925 \mathrm{hPa}$ and between $0^{\circ}$ and $30^{\circ} \mathrm{W}$ ) centered around the high peaks ( $30 \mathrm{~K} \mathrm{~m} \mathrm{~s}^{-1}$ or higher) in both $v^{\prime} T^{\prime}$ and $\overline{v^{\prime} T^{\prime}}$ were plotted, along with the composites of heat flux and baroclinicity, in Fig. 9. Both cases exhibit a similar behavior of heat flux and baroclinicity. Consistent with AN's mechanism, the buildup of baroclinicity is shortly followed by a rapid increase in the heat flux. Following this substantial increase in the heat flux the baroclinicity falls to low values. Consequently, the heat flux is reduced and the baroclinicity increases again. It is apparent, however, that this oscillation cycle of heat flux and 


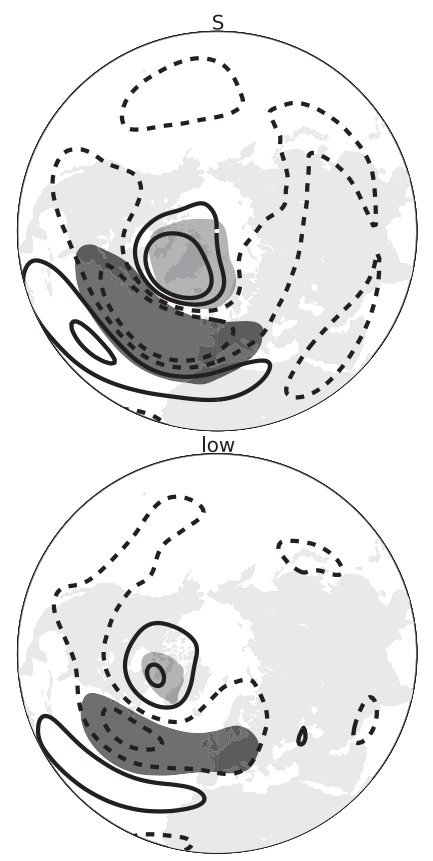

$850 \mathrm{hPa}\left(>2 \times 10^{6} \mathrm{~m}^{2} \mathrm{~s}^{-1}\right)$

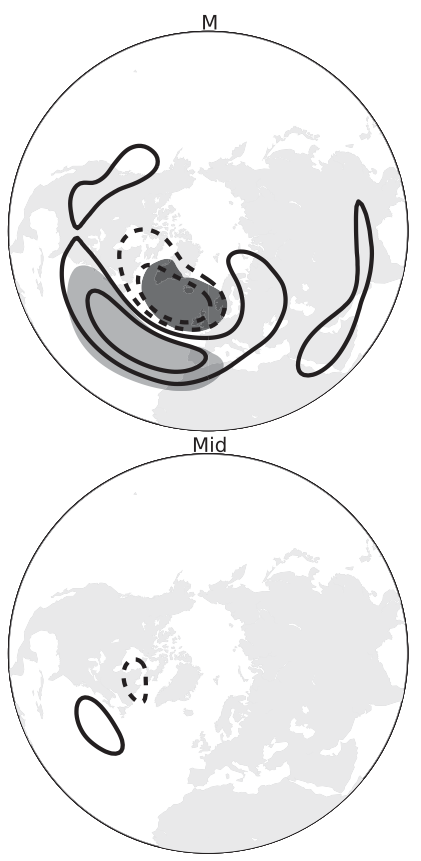

$850 \mathrm{hPa}\left(<-2 \times 10^{6} \mathrm{~m}^{2} \mathrm{~s}^{-1}\right)$

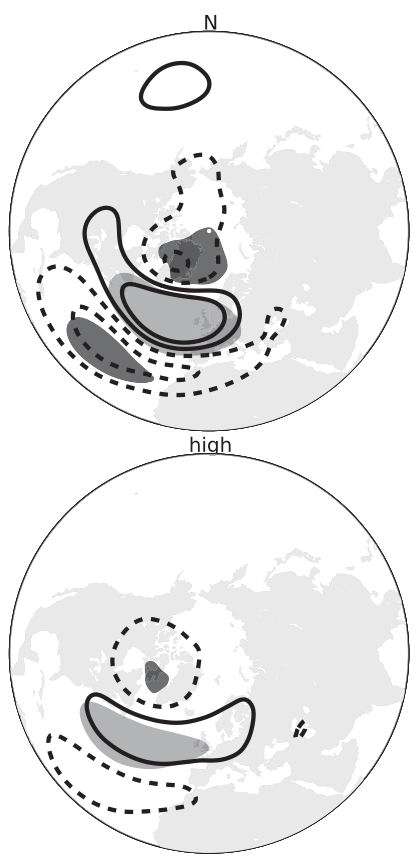

$250 \mathrm{hPa}\left(2 \times 10^{6}, 6 \times 10^{6} \mathrm{~m}^{2} \mathrm{~s}^{-1}\right) \quad---250 \mathrm{hPa}\left(-2 \times 10^{6},-6 \times 10^{6} \mathrm{~m}^{2} \mathrm{~s}^{-1}\right)$

FIG. 8. Composites of the upper-level $(250 \mathrm{hPa})$ and lower-level $(850 \mathrm{hPa})$ streamfunction anomalies for the (top) jet regimes and (bottom) heat flux terciles. Please see supplemental material at http://dx.doi.org/10.1175/JAS-D-14-0082.s1 for a color version of these composites.

baroclinicity in the $\overline{v^{\prime} T^{\prime}}$-centered composite operates on a longer time scale. It is also evident from the figure that only a small change in the jet latitude can be observed for the $v^{\prime} T^{\prime}$-centered composite following the shortterm dip (of less than 3 days) in baroclinicity, whereas the jet was found to move north by approximately $5^{\circ}$ a day after the peak in $\overline{v^{\prime} T^{\prime}}$ and a longer-term dip (of approximately 6 days) in baroclinicity.

In the previous section we noted that the filtered heat flux is composed of an accumulation of $v^{\prime} T^{\prime}$ events or one large event. To test this we examined all of the 10-day windows that were used to produce Fig. $9 \mathrm{~b}$ using a simple algorithm. For each window, this algorithm uses a 1-2-1 filter to smooth $v^{\prime} T^{\prime}$ and then counts all peaks in the smoothed $v^{\prime} T^{\prime}$ that are higher than the maximum value of the $\overline{v^{\prime} T^{\prime}}$ in that window. It additionally neglects the marginal points of days $-5,-4,4$, and 5 .

TABLE 3. Correlation scores for the $850-\mathrm{hPa}$ streamfunction anomaly of the patterns in Fig. 8 for the $\mathrm{S}, \mathrm{M}$, and $\mathrm{N}$ jet regimes and low, middle, and high $\overline{v^{\prime} T^{\prime}}$ terciles.

\begin{tabular}{lrrr}
\hline & Low & Middle & High \\
\hline S & 0.83 & -0.58 & -0.79 \\
M & -0.37 & 0.57 & 0.32 \\
$\mathrm{~N}$ & -0.61 & 0.13 & 0.62 \\
\hline
\end{tabular}

Although it is difficult to define an individual spike unequivocally, visual inspection confirmed that this is a reasonable method of counting the major spikes. The results are shown in Table 5. It is apparent that over a half of the $\overline{v^{\prime} T^{\prime}}$ peaks are composed of two- $v^{\prime} T^{\prime}$-spike events and about a quarter is composed of one- $v^{\prime} T^{\prime}$-spike events. The rest is mostly three- $v^{\prime} T^{\prime}$-spike events. We also plotted the equivalent of Fig. 9b for the one-, two-, and three-spike events (not shown) and found that they all yield a similar northward shift in the jet. This implies that even one strong storm is capable of shifting the jet. Inspection of the $v^{\prime} T^{\prime}$ PDF (not shown) revealed that such high $v^{\prime} T^{\prime}$ spikes are common in both the $\mathrm{M}$ and $\mathrm{N}$ regimes but are more frequent during the latter regime.

This section suggests that the cycling between the jet regimes is, at least to some extent, a result of the

TABLE 4. Correlation scores for the $250-\mathrm{hPa}$ streamfunction anomaly of the patterns in Fig. 8 for the $\mathrm{S}, \mathrm{M}$, and $\mathrm{N}$ jet regimes and low, middle, and high $\overline{v^{\prime} T^{\prime}}$ terciles.

\begin{tabular}{lrrr}
\hline & Low & Middle & High \\
\hline $\mathrm{S}$ & 0.74 & -0.27 & -0.64 \\
$\mathrm{M}$ & -0.25 & 0.41 & 0.11 \\
$\mathrm{~N}$ & -0.57 & -0.07 & 0.60 \\
\hline
\end{tabular}


(a)

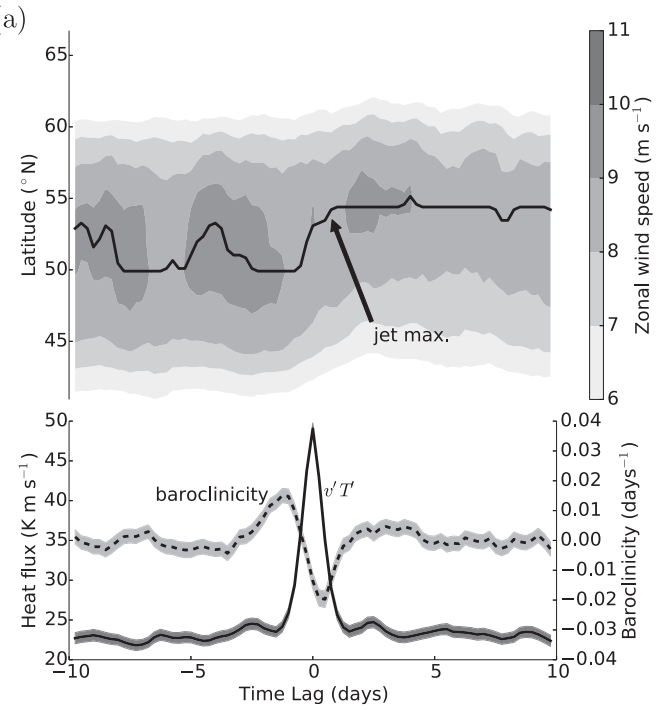

(b)

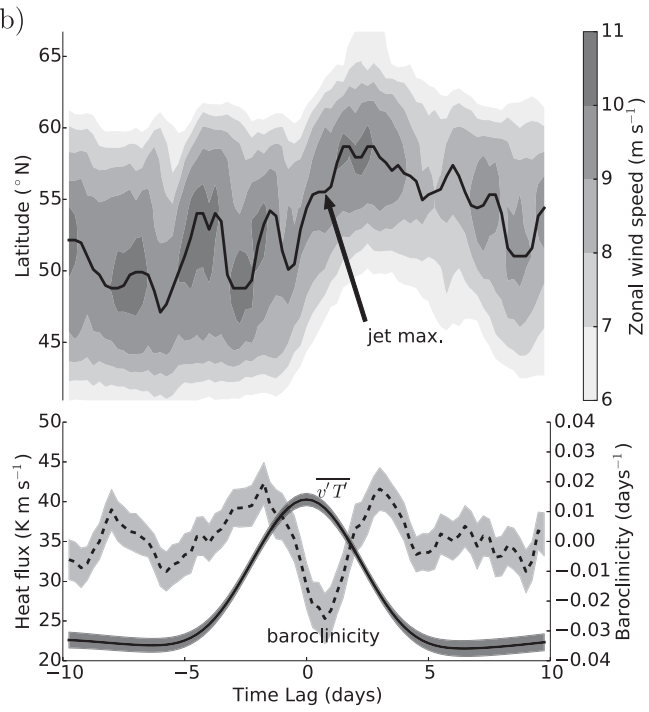

FIG. 9. (bottom) Composites of the (a) unfiltered and (b) filtered heat flux (solid; averaged between $35^{\circ}$ and $50^{\circ} \mathrm{N}$ and between $40^{\circ}$ and $70^{\circ} \mathrm{W}$ ) and baroclinicity (dashed; averaged between $30^{\circ}$ and $50^{\circ} \mathrm{N}$ and between $30^{\circ}$ and $90^{\circ} \mathrm{W}$ ). The composites are centered around the maxima (higher than $30 \mathrm{~K} \mathrm{~m} \mathrm{~s}^{-1}$ ) of the respective heat flux variables. Baroclinicity is the excess baroclinicity as defined in AN and the mean offset is $0.52 \mathrm{day}^{-1}$. The shading indicates the standard mean errors. (top) Composites of the lower-level zonal wind (averaged between $0^{\circ} \mathrm{W}$ and $30^{\circ}$ and between 700 and $925 \mathrm{hPa}$ ) are marked by the grayscale filled contours and the jet maximum is also displayed. For higher temporal resolution, these figures are based on 6-hourly ERA-40 data.

longer-term effect of the nonlinear equilibration of zonally oriented synoptic baroclinic eddies. These eddies cumulatively give rise to meridionally oriented patterns [as suggested by Benedict et al. (2004)], similar to those in Hannachi et al. (2012) that represent different phases of the North Atlantic Oscillation (NAO) and the East Atlantic Oscillation (EA). This concurs with the results of Athanasiadis and Ambaum (2009), which suggest that the only way synoptic eddies (associated with propagating wave trains across the hemisphere) can contribute to teleconnections is through interaction with lower-frequency waves. The jet regime and heat flux tercile sets are not identical, but it can be concluded that high-heat-flux events are associated with a more northern shift of the jet, whereas low-heat-flux events are associated with a southern shift of the jet.

\section{Discussion and conclusions}

The results of this study suggest that variations in stormtrack activity (in particular, lower-level meridional heat flux) during the North Atlantic jet regimes have a dual effect on the jet characteristics: a direct upstream baroclinic effect that strengthens and weakens the jet's wind shear (and thus baroclinicity) and a downstream barotropic effect that results in shifts in the jet's latitude and intensity.

The upstream effect is not in a steady state but oscillates because of a nonlinear oscillator relationship between the heat flux and lower-level baroclinicity, as proposed by AN. On longer time scales of the filtered heat flux, this relationship yields preferred transitions between the jet regimes that are from $\mathrm{M}$ to $\mathrm{N}, \mathrm{N}$ to $\mathrm{S}$, and S to M [as suggested by Franzke et al. (2011)]. High baroclinicity during the $\mathrm{M}$ regime produces high stormtrack activity. These storms will develop further, mix the temperature gradients, and thus reduce baroclinicity, corresponding to the $\mathrm{N}$ regime. The storm-track activity will eventually weaken as the low baroclinicity can no longer sustain it. This corresponds to the $\mathrm{S}$ regime with low storm-track activity and a replenishing baroclinicity. Further increases in baroclinicity will lead to further increases in storm-track activity and the cycle repeats.

The downstream effect of the storm-track activity variability on the jet is closely dependent on the upstream effect and is based on the idea that different values in baroclinicity may induce different eddy anisotropy and wave breaking that would result in latitudinal shifts in the jet (Orlanski 2003). We therefore

TABLE 5. Count of $\overline{v^{\prime} T^{\prime}}$ events over $30 \mathrm{~K} \mathrm{~m} \mathrm{~s}^{-1}$ that were composed of one, two, three, and four $v^{\prime} T^{\prime}$ spikes over that value. More detail of the method employed to obtain these counts is given in the text.

\begin{tabular}{cccc}
\hline \hline One spike & Two spikes & Three spikes & Four spikes \\
\hline 33 & 73 & 25 & 2 \\
\hline
\end{tabular}


studied the eddy anisotropy, PV distribution, and $\mathbf{E}$ vectors to test whether this mechanism is responsible for the changing jet characteristics during the jet regimes. We found that the $\mathrm{N}$ regime is most dominated by anticyclonic wave breaking and the $\mathrm{S}$ regime experiences most extensive cyclonic wave breaking, with the $\mathrm{M}$ regime exhibiting a strong influence of both wave breaking types. These patterns are consistent with what would be expected from the observed baroclinicity patterns according to Orlanski's (2003) theory. The E vectors further show that high-frequency eddies are to some extent responsible for these large-scale patterns and latitudinal jet deflection during the regimes.

The above cyclical spatiotemporal changes in eddy properties, propagation, and breaking during the jet regimes can be viewed as the life cycle of the storm track. The different stages of this life cycle can be described as follows. Baroclinicity is continuously replenished by diabatic forcing. When the storm-track activity is low, the baroclinicity will increase and start to form round and coherent eddies. This will contribute to the strengthening of the large-scale trough over the western Atlantic inducing large-scale cyclonic wave breaking (associated with an anticyclonic anomaly over Greenland and a cyclonic anomaly over the storm track), which will steer the jet south (S regime). Further increases of baroclinicity will further enhance cyclonic breaking. However, at the same time, eddies will become more vigorous and propagate farther downstream. As a result, the influence of the cyclonic breaking on the poleward side of the jet is overridden by the influence of the increased anticyclonic breaking on the equatorward side of the jet because of the enhanced eddy deformation. The resultant jet position is slightly more poleward ( $\mathrm{M}$ regime). In the next stage, eddy activity becomes so large that the eddy mixing rapidly reduces the baroclinicity, overriding the replenishing effect of the diabatic forcing. The reduced baroclinicity inhibits the production of new storms and enables the eddies to deform farther upstream. The anticyclonic breaking starts to dominate as the large-scale ridge in the eastern Atlantic strengthens (and induces an anticyclonic anomaly over the end of the storm track and a low over Greenland), steering the jet farther poleward ( $\mathrm{N}$ regime). Once the remaining eddy activity decays, the baroclinicity can be replenished by the diabatic forcing again (S regime) and the cycle repeats.

Because the downstream effect is dependent on the upstream effect, both effects will oscillate in time. However, these oscillations do not correlate completely owing to their inherently different time scales. The upstream erosion of baroclinicity by high-heat-flux events occurs almost immediately (as shown in AN), resulting in high-frequency correlated variability in both variables. This study demonstrated that an accumulation of such heat flux events also results in lower-frequency oscillations of both heat flux and baroclinicity, which have an approximately weekly time scale that is similar to that of the jet regimes. While we found that a shortterm heat flux event is only followed by a slight shift in the jet latitude, this shift is significantly magnified when an accumulation of such events (or a particularly large one) precedes it. It has been found that a dominant type of wave breaking can persist for longer than an individual eddy, thereby enabling a transition from highto low-frequency variability (Benedict et al. 2004). This may explain why the downstream effect of shifting the jet is much more prominent on the longer time scales, while the nonlinear oscillator relationship between heat flux and baroclinicity operates on both short and long time scales.

As hinted upon in section 3 and confirmed in previous studies (e.g., Woollings et al. 2010), the jet regimes are related to the teleconnection patterns, such as NAO and EA. While teleconnections are not the focus of this paper, it is useful to compare our results to the existing literature to strengthen the validity of our conclusions. For example, Pinto et al.'s (2009) analysis of cyclone "Daria" shows that its onset in the western Atlantic was shortly followed by an increase in the NAO index that translates to a northern shift of the jet. Several days later the NAO index decreased as the storm left the upstream region, reflecting the characteristics of the $\mathrm{S}$ regime. Similarly, Woollings et al. (2011) find an increase in eddy activity in situ immediately before the onset of enhanced anticyclonic upper-level wave breaking (i.e., northern shift in the jet) without the need of preconditioned flow from the Pacific. In addition, Mailier et al. (2006) emphasize that there is a strong link between teleconnections and clustering of extratropical cyclones, which is associated with changing values of baroclinicity. Further support comes from Feldstein (2003), who suggests that high-frequency eddies are essential for driving low-frequency patterns, such as NAO. Similarly, Athanasiadis and Ambaum (2010) showed that highfrequency eddies contribute to teleconnection tendencies by a nonlinear transfer from high to low frequencies. All the above studies confirm our conclusion that local variability of high-frequency eddy activity induces lower-frequency variability in the downstream jet.

Throughout this study we suggest that the cyclic behavior of the storm track is a purely local phenomenon. However, it is clear (e.g., from the time series in Fig. 4 of AN) that these storm-track life cycles are irregular and that other sources of variability are present. It is inevitable that, unlike in AN's simplified model, the 
diabatic heating that replenishes the region of enhanced baroclinicity will vary on many time scales. Furthermore, as suggested in the introduction, there are other mechanisms (other than modifying baroclinicity) that can induce transitions between different types of wave breaking and therefore cause latitudinal shifts in the jet. For example, several studies (e.g., Thorncroft et al. 1993; Franzke et al. 2004; Rivière and Orlanski 2007; Pinto et al. 2011) suggest that preconditioning the flow with barotropic shear can play a significant role in determining the polarity of the NAO index (and thus the jet latitude). This study, however, only reveals a weak variability outside of the North Atlantic basin during the jet regimes, which would imply that the North Atlantic and North Pacific jets are not strongly linked on the time scales of the jet regimes [as found, for example, by Blackmon et al. (1984) and Ambaum et al. (2001)]. We speculate that while high-frequency eddies propagate across the hemisphere as zonally oriented wave trains (e.g., Gerber and Vallis 2007), their enhancement and shaping across the North Atlantic basin is a local phenomenon (Chang et al. 2002) that will affect local patterns of teleconnections and thus induce lowerfrequency variations in the local jet's latitude. It is nevertheless still possible that the averaging methods employed in this investigation obscured some external variability outside of the North Atlantic. In addition, while Wittman et al. (2004) conclude that stratospheric changes yield a relatively small response of the tropospheric flow, they note that constant exposure during several baroclinic life cycles may produce a more significant tropospheric response. This aspect was not studied here and requires further attention.

In terms of broader applicability, the anomalous spikes in heat flux can be observed for all terrestrial storm tracks (Messori and Czaja 2013), but not all exhibit the observed trimodal fluctuations in jet latitude (Woollings et al. 2010). For example, the Pacific-North America pattern is largely dominated by the pulsation of the jet rather than the latitudinal shifts as a consequence of the stationary eddies being dominant (Franzke and Feldstein 2005). It is possible that these fluctuations in jet intensity in the Pacific region are also a result of baroclinicity erosion by heat flux. The two storm tracks do not appear to be significantly correlated, meaning that different time scales would apply. Woollings et al. (2010) find that the latitudinal PDFs of the jets in the South Pacific and central North Pacific both exhibit a bimodal structure, corresponding to whether the eddydriven jet is merged with the subtropical jet. They associated the trimodal structure of the North Atlantic jet to the stationary wave configuration that tilts the storm track (and the jet) more poleward than in any of the other regions. It is therefore possible that while the organization into flow regimes is a general characteristic of all storm tracks, the relatively weak subtropical jet over the North Atlantic and the stationary wave forcing allow the North Atlantic jet to exhibit a more complex latitudinal variability because of transient eddies. Additional investigation of the other two storm tracks may separate the individual roles played by stationary and transient eddies and determine more generally their relative contribution to the spatiotemporal life cycle of the storm track.

Acknowledgments. Lenka Novak is supported by the U.K. Natural Environment Research Council (Grant NE/K500860/1). We thank T. Frame for providing the jet regime classification dataset and J. G. Pinto for his comments on an earlier draft of this paper.

\section{REFERENCES}

Ambaum, M. H. P., and L. Novak, 2014: A nonlinear oscillator describing storm track variability. Quart. J. Roy. Meteor. Soc., 140, 2680-2684, doi:10.1002/qj.2352.

_ B. J. Hoskins, and D. B. Stephenson, 2001: Arctic Oscillation or North Atlantic Oscillation? J. Climate, 14, 3495-3507, doi:10.1175/1520-0442(2001)014<3495:AOONAO > 2.0.CO;2.

Athanasiadis, P., and M. H. P. Ambaum, 2009: Linear contributions of different time scales to teleconnectivity. J. Climate, 22, 3720-3728, doi:10.1175/2009JCLI2707.1.

— , and - 2010: Do high-frequency eddies contribute to lowfrequency teleconnection tendencies? J. Atmos. Sci., 67, 419433, doi:10.1175/2009JAS3153.1.

Benedict, J. J., S. Lee, and S. B. Feldstein, 2004: Synoptic view of the North Atlantic Oscillation. J. Atmos. Sci., 61, 121-144, doi:10.1175/1520-0469(2004)061<0121:SVOTNA > 2.0.CO;2.

Blackmon, M. L., Y.-H. Lee, and J. M. Wallace, 1984: Horizontal structure of $500 \mathrm{mb}$ height fluctuations with long, intermediate and short time scales. J. Atmos. Sci., 41, 961-980, doi:10.1175/ 1520-0469(1984)041<0961:HSOMHF>2.0.CO;2.

Brayshaw, D. J., B. Hoskins, and M. Blackburn, 2011: The basic ingredients of the North Atlantic storm track. Part II: Sea surface temperatures. J. Atmos. Sci., 68, 1784-1805, doi:10.1175/2011JAS3674.1.

Chang, E., S. Lee, and K. L. Swanson, 2002: Storm track dynamics. J. Climate, 15, 2163-2183, doi:10.1175/1520-0442(2002)015<02163: STD $>2.0 . C O ; 2$.

Duchon, C. E., 1979: Lanczos filtering in one and two dimensions. J. Appl. Meteor., 18, 1016-1022, doi:10.1175/ 1520-0450(1979)018<1016:LFIOAT>2.0.CO;2.

Feldstein, S. B., 2003: The dynamics of NAO teleconnection pattern growth and decay. Quart. J. Roy. Meteor. Soc., 129, 901924, doi:10.1256/qj.02.76.

Frame, T. H., M. H. P. Ambaum, S. S. Gray, and J. Methven, 2011: Ensemble prediction of transitions of the North Atlantic eddydriven jet. Quart. J. Roy. Meteor. Soc., 137, 1288-1297, doi:10.1002/qj.829.

Franzke, C., and S. B. Feldstein, 2005: The continuum and dynamics of Northern Hemisphere teleconnection patterns. J. Atmos. Sci., 62, 3250-3267, doi:10.1175/JAS3536.1. 
— S. Lee, and S. B. Feldstein, 2004: Is the North Atlantic Oscillation a breaking wave? J. Atmos. Sci., 61, 145-160, doi:10.1175/1520-0469(2004)061<0145:ITNAOA > 2.0.CO;2.

_ T. Toollings, and O. Martius, 2011: Persistent circulation regimes and preferred regime transitions in the North Atlantic. J. Atmos. Sci., 68, 2809-2825, doi:10.1175/JAS-D-11-046.1.

Gerber, E. P., and G. K. Vallis, 2007: Eddy-zonal flow interactions and the persistence of the zonal index. J. Atmos. Sci., 64, 32963311, doi:10.1175/JAS4006.1.

Hannachi, A., T. Woolings, and K. Fraedrich, 2012: The North Atlantic jet stream: A look at preferred positions, paths and transitions. Quart. J. Roy. Meteor. Soc., 138, 862-877, doi:10.1002/qj.959.

Hoskins, B., and P. J. Valdes, 1990: On the existence of storm-tracks. J. Atmos. Sci., 47, 1854-1864, doi:10.1175/1520-0469(1990)047<1854: OTEOST $>2.0 . \mathrm{CO} ; 2$.

- I. James, and G. White, 1983: The shape, propagation and mean-flow interaction of large-scale weather systems. J. Atmos. Sci., 40, 1595-1612, doi:10.1175/1520-0469(1983)040<1595: TSPAMF $>2.0 . \mathrm{CO} ; 2$.

James, I. N., 1994: Introduction to Circulating Atmospheres. Cambridge University Press, $230 \mathrm{pp}$.

Lorenz, D. J., and D. L. Hartmann, 2003: Eddy-zonal flow feedback in the Northern Hemisphere winter. J. Climate, 16, 1212-1227, doi:10.1175/1520-0442(2003)16<1212:EFFITN>2.0.CO;2.

Mailier, P. J., D. B. Stephenson, C. A. T. Ferro, and K. I. Hodges, 2006: Serial clustering of extratropical cyclones. Mon. Wea. Rev., 134, 2224-2240, doi:10.1175/MWR3160.1.

Messori, G., and A. Czaja, 2013: On the sporadic nature of meridional heat transport by transient eddies. Quart. J. Roy. Meteor. Soc., 139, 999-1008, doi:10.1002/qj.2011.

Namias, J., 1950: The index cycle and its role in the general circulation. J. Meteor., 7, 130-139, doi:10.1175/1520-0469(1950)007<0130: TICAIR $>2.0 . \mathrm{CO} ; 2$.

Orlanski, I., 1998: Poleward deflection of storm tracks. J. Atmos. Sci., 55, 2577-2602, doi:10.1175/1520-0469(1998)055<2577: PDOST $>2.0 . \mathrm{CO} ; 2$.

_ 2003: Bifurcation in eddy life cycles: Implications for storm track variability. J. Atmos. Sci., 60, 993-1023, doi:10.1175/ 1520-0469(2003)60<993:BIELCI > 2.0.CO;2.

Pinto, J. G., S. Zacharias, A. H. Fink, G. C. Leckebusch, and U. Ulbrich, 2009: Factors contributing to the development of extreme North Atlantic cyclones and their relationship with the NAO. Climate Dyn., 32, 711-737, doi:10.1007/s00382-008-0396-4.
- M. Reyers, and U. Ulbrich, 2011: The variable link between PNA and NAO in observations and in multi-century CGCM simulations. Climate Dyn., 36, 337-354, doi:10.1007/ s00382-010-0770-x.

Rivière, G., 2009: Effect of latitudinal variations in low-level baroclinicity on eddy life cycles and upper-tropospheric wave-breaking processes. J. Atmos. Sci., 66, 1569-1592, doi:10.1175/2008JAS2919.1.

- , and I. Orlanski, 2007: Characteristics of the Atlantic stormtrack eddy activity and its relation with the North Atlantic Oscillation. J. Atmos. Sci., 64, 241-266, doi:10.1175/ JAS3850.1.

Sanders, F., and J. R. Gyakum, 1980: Synoptic-dynamic climatology of the "bomb." Mon. Wea. Rev., 108, 1589-1606, doi:10.1175/1520-0493(1980)108<1589:SDCOT>2.0.CO;2.

Thompson, D. W. J., and T. Birner, 2012: On the linkages between the tropospheric isentropic slope and eddy fluxes of heat during Northern Hemisphere winter. J. Atmos. Sci., 69, 18111823, doi:10.1175/JAS-D-11-0187.1.

Thorncroft, C. D., B. J. Hoskins, and M. E. McIntyre, 1993: Two paradigms of baroclinic wave life-cycle behaviour. Quart. J. Roy. Meteor. Soc., 119, 17-55, doi:10.1002/qj.49711950903.

Uppala, S. M., and Coauthors, 2005: The ERA-40 Re-Analysis. Quart. J. Roy. Meteor. Soc., 131, 2961-3012, doi:10.1256/ qj.04.176.

von Storch, H., and F. W. Zwiers, 1999: Statistical Analysis in Climate Research. Cambridge University Press, 494 pp.

Wittman, M., R. Scott, and A. Charlton, 2004: Stratospheric influence on baroclinic lifecycles: Connection to the Arctic Oscillation. Geophys. Res. Lett., 31, L16113, doi:10.1029/ 2004GL020503.

- A. Charlton, and L. Polvani, 2007: The effect of lower stratospheric shear on barclinic instability. J. Atmos. Sci., 64, 479-496, doi:10.1175/JAS3828.1.

Woollings, T., B. Hoskins, M. Blackburn, and P. Berrisford, 2008: A new Rossby wave-breaking interpretation of the North Atlantic Oscillation. J. Atmos. Sci., 65, 609-626, doi:10.1175/ 2007JAS2347.1.

— A. Hannachi, and B. Hoskins, 2010: Variability of the North Atlantic eddy-driven jet stream. Quart. J. Roy. Meteor. Soc., 136, 856-868, doi:10.1002/qj.625.

_ J. G. Pinto, and J. A. Santos, 2011: Dynamical evolution of North Atlantic ridges and poleward jet stream displacements. J. Atmos. Sci., 68, 954-963, doi:10.1175/2011JAS3661.1. 